\title{
Anomaly Diagnosis Analysis for Running Meter Based on BP Neural Network
}

\author{
Zhengye Wang ${ }^{1,2, *}$, Gangjun Gong ${ }^{1,2}$ and Yafeng Wen $^{1}$ \\ ${ }^{1}$ North China Electric Power University, No.2, Beinong Road, Huilongguan Town, Changping District, Beijing, China \\ ${ }^{2}$ Beijing Engineering Research Center of Energy Electric Power Information Security, No.2, Beinong Road, Huilongguan Town, \\ Changping District, Beijing, China \\ Corresponding author
}

\begin{abstract}
Smart meters is important equipment in the electric information acquisition system, it is the terminal equipment on the user side to realize information collection, energy metering and other functions. However, because of maintenance workload greatly, artificial detection can't meet the need. In this paper, anomaly diagnosis analysis for running meter is proposed, by dealing with data collected, setting up diagnosis model, realize maintain for smart meter.
\end{abstract}

Keywords-BP neural network; electric meter; anomaly diagnosis

\section{INTRODUCTION}

Over the course of the past 10years, to realize the goal of "full coverage, full collection, full fee charged", every provincial power company are actively advance of the construction electricity information collection system, the system acquisition success rate has been significantly increased, so as other corresponding application [1]. In this system, smart meter is important equipment to measure electricity, related to the interests of thousands of power users, received widespread attention. Therefore, research of abnormal diagnosis on running meters has the vital significance.

\section{SMART METER}

Electricity information acquisition system involves the main station, communication network, acquisition terminal, installation and maintenance etc. Operation condition of the smart meter largely determines the whole system practical application effect, however, now the artificial detection has been difficult to adapt to the needs of the grid situation.

In this article, the diagnosis to smart meters is mainly for residential users, according to the function The electric meter hardware structure can be divided into two parts: electric energy acquisition part and power information processing part, the concrete can be divided into measurement module, communication module, clock module, memory module, display module, power module and other parts [2]. As shown in Figure I.

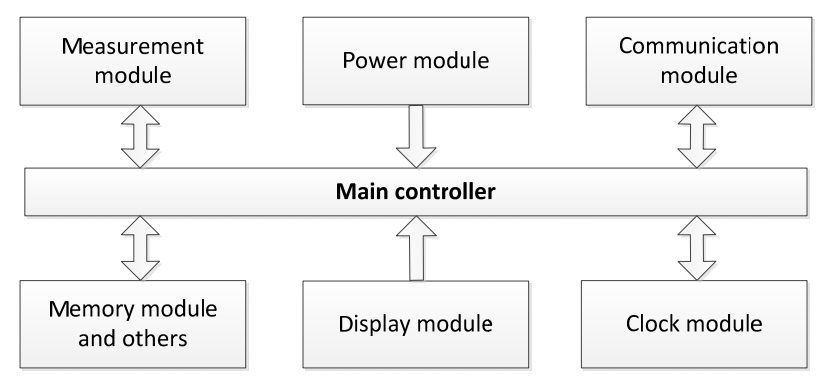

FIGURE I. THE FUNCTION BLOCK DIAGRAM OF SMART METER

\section{THE BP NEURAL NETWORK}

BP neural network is the core part of the feedforward network, has the function of dealing with complex multimodal reasoning and memory, the good nonlinear mapping ability of $\mathrm{BP}$ neural network can be a good application in fault diagnosis.

As shown in Figure II, Typical of the BP neural network consists of an input layer, an output layer and at least one hidden layer [3]. Among them, $x_{1}, x_{2}, \cdots, x_{n}$ are the BP neural network input values, $y_{1}, \cdots, y_{q}$ are the BP neural network output values, $\omega 1_{i h}$ and $\omega 2_{\text {ho }}$ the weights of BP neural network. When the number of input layer neurons is $\mathrm{N}$, the output number is $\mathrm{Q}$, the BP network is done the function mapping relationship which is $\mathrm{N}$ to $\mathrm{Q}$.

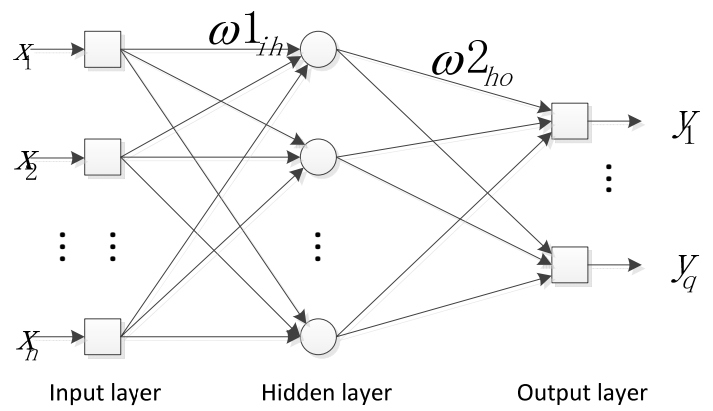

FIGURE II. THE STRUCTURE OF BP NEURAL NETWORK 


\section{BP NEURAL NetWork FOR ABNORMAL DiAgNosis}

Abnormality diagnosis of electric meter is based on single anomaly monitoring, obtained from some typical faults of electric meter as samples for the BP neural network to train, so the network has judgment ability, a model for abnormality diagnosis is got.

\section{A. Anomaly Correlation Analysis}

There are complex and nonlinear relations between the fault symptoms and fault types, in order to improve the accurate of fault diagnosis, this paper combined conditions of all kinds of data, correlation, and other related business application requirements, establish an abnormal diagnosis correlation analysis table as Table I.

TABLE I. ABNORMAL DIAGNOSIS CORRELATION

\begin{tabular}{|c|c|c|c|}
\hline single anomaly & $\begin{array}{c}\text { Measuring } \\
\text { module } \\
\text { failure }\end{array}$ & $\begin{array}{c}\text { Clock } \\
\text { module } \\
\text { failure }\end{array}$ & $\begin{array}{c}\text { Communication } \\
\text { module failure }\end{array}$ \\
\hline Value error & 0.5 & & \\
\hline Flowed too fast & 0.4 & & \\
\hline Flowed backwards & 0.4 & & \\
\hline Abnormal clock & & 0.7 & \\
\hline $\begin{array}{c}\text { History } \\
\text { communication } \\
\text { success rate }\end{array}$ & & & 0.7 \\
\hline $\begin{array}{c}\text { Fees charged } \\
\text { success rate }\end{array}$ & & & 0.7 \\
\hline
\end{tabular}

\section{B. Access to the Training Sample}

Data in anomaly diagnosis analysis is mainly based on the electricity information collection system, collected by the main station from terminals, processed as the principle of signal abnormal data [4]. The six signal exception is represented $x_{1}, x_{2}, \cdots x_{6}$, put data into the formula, take 1 is true, otherwise 0 . The three failures are represented as $y_{1}, y_{2}, y_{3}$, when the module is fault, $y_{i}(i=1,2,3)$ is 1 . After processing, the samples for training can be got, shown as Table II.

TABLE II. TRAINING SAMPLES

\begin{tabular}{|c|c|c|c|}
\hline $\begin{array}{c}\text { serial } \\
\text { numbe } \\
\text { r }\end{array}$ & Input & Output & Fault types \\
\hline 1 & {$\left[\begin{array}{lllllll}1 & 0 & 0 & 0 & 0 & 0\end{array}\right]$} & {$\left[\begin{array}{lll}1 & 0 & 0\end{array}\right]$} & Measuring module failure \\
\hline 2 & {$\left[\begin{array}{lllllll}0 & 0 & 0 & 1 & 0 & 0\end{array}\right]$} & {$\left[\begin{array}{lll}0 & 1 & 0\end{array}\right]$} & Clock module failure \\
\hline$\cdots$ & $\ldots \ldots \ldots \cdots$ & $\ldots \ldots \ldots$ & $\ldots \ldots \ldots \cdots \cdots$ \\
\hline 16 & {$\left[\begin{array}{lllllll}0 & 0 & 0 & 0 & 1 & 1\end{array}\right]$} & {$\left[\begin{array}{lll}0 & 0 & 1\end{array}\right]$} & Communication module failure \\
\hline
\end{tabular}

\section{Simulation, Diagnosis and Analysis}

In this paper, the software of simulation experiment is the MATLAB software, set the mean square error is 0.065 , the learning rate is 0.05 , and the structure is $6-7-3$, the number of input layer neurons and output layer neurons is determined by the application requirements, they are six and three, the number of hidden layer neurons is choose seven. After the 57th iteration training, the mean square error has reached the requirement of less than 0.065 , the hidden layer threshold respectively is $-1.7821,1.3790,-0.6502,0.0558,0.9337$, $1.3565,2.0674$, the output layer threshold respectively is 1.3039, $-0.2452,-1.5434$, connection weights as Table III and Table IV, and the curve of mean square error is shown in Figure III.

TABLE III. CONNECTION WEIGHTS OF INPUT LAYER TO HIDDEN LAYER

\begin{tabular}{|c|c|c|c|c|c|c|}
\hline$\omega 1_{i h}$ & 1 & 2 & 3 & 4 & 5 & 6 \\
\hline 1 & 0.7259 & -1.0496 & -0.8585 & -1.1115 & 0.1733 & -0.6915 \\
\hline 2 & -0.3309 & -0.7126 & -0.6699 & 0.4574 & 1.3706 & 0.8939 \\
\hline 3 & 0.4348 & 0.9939 & 0.8382 & -0.9825 & -0.9549 & 0.1595 \\
\hline 4 & 0.8698 & -0.2221 & 0.0162 & 0.7344 & -1.1456 & -1.0945 \\
\hline 5 & -0.1816 & -0.8156 & 0.0300 & -0.7343 & -1.0952 & -0.9741 \\
\hline 6 & -0.5079 & -0.9837 & 0.3303 & 0.9277 & 0.4747 & -0.9656 \\
\hline 7 & 1.0817 & 0.8973 & 0.3975 & -0.7817 & 0.2910 & 0.7819 \\
\hline
\end{tabular}

TABLE IV. CONNECTION WEIGHTS OF HIDDEN LAYER TO OUTPUT LAYER

\begin{tabular}{|c|c|c|c|}
\hline$\omega 2_{h o}$ & 1 & 2 & 3 \\
\hline 1 & -0.3938 & -0.4336 & -0.4850 \\
\hline 2 & -1.1346 & 0.6317 & 0.7984 \\
\hline 3 & 0.8189 & 0.2019 & -0.3071 \\
\hline 4 & -0.0896 & 0.7563 & -1.1303 \\
\hline 5 & -0.7216 & -0.9020 & 0.8507 \\
\hline 6 & 0.7878 & -0.1370 & -0.0482 \\
\hline 7 & 0.4418 & -0.9717 & 0.5431 \\
\hline
\end{tabular}

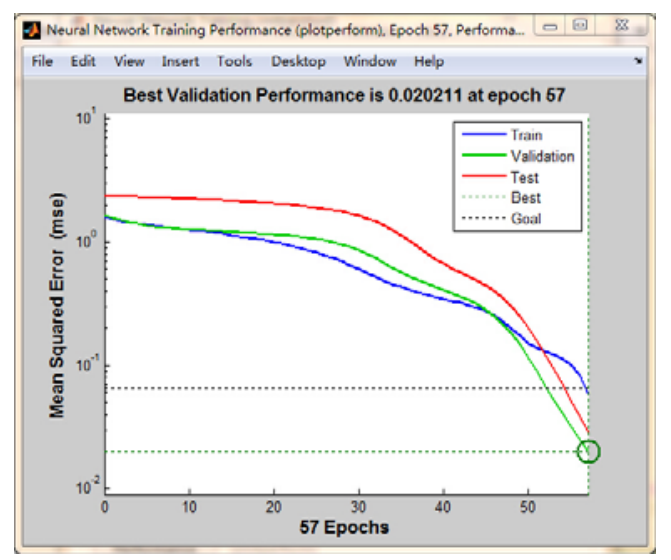

FIGURE III. THE CURVE OF MEAN SQUARE ERROR 
Fault diagnosis use the neural network after training, input diagnosis samples to the neural network, as a result, the failure of the network output and the actual contrast diagram as shown in Figure IV.

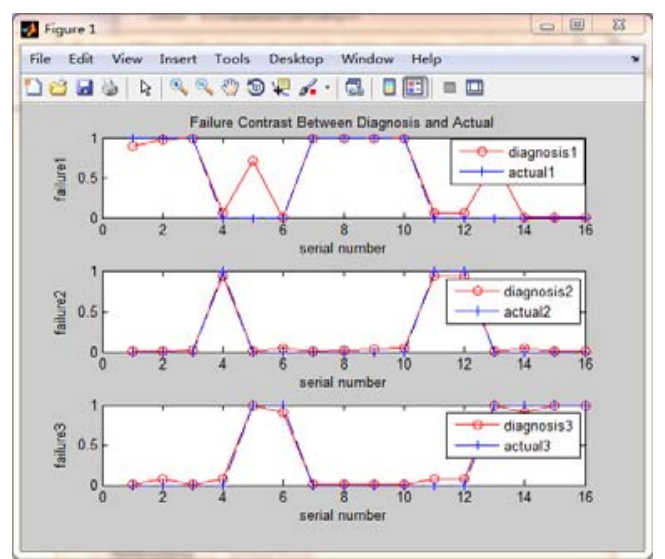

FIGURE IV. FAILURE BETWEEN NETWORK OF SMART METER

We can get from Figure IV, output and the actual output of the neural network diagnosis is quite close, achieved the requirement of the training, so the anomaly diagnosis for meter based on BP neural network is feasible.

\section{SUMMARY}

In this paper, anomaly diagnosis for running meter is studied, the model is established by BP neural network which is used widely, organized multiple samples to train and optimize, process the output data by the principle of maximum membership. The result shows that the network output is closely to ideal, so the anomaly diagnosis for running meter based on BP neural network proposed in this paper is feasible and can be used in practical application.

\section{ACKNOWLEDGEMENTS}

The work was supported by a general program from the Basic Science Research Fund of Central Universities (No.JB2014048).

\section{REFERENCES}

[1] HU Jiangyi, ZHU Enguo, DU Xingang, DU Shuwei. “Application Status and Development Trend of Power Consumption Information Collection System”. Automation of Electric Power Systems, 2014, 02: 131-135.

[2] ZHANG Wen. "The Design and Implementation of Fault Analysis of The Smart Meter Data Acquisition”. Chengdu: School of Information and Software Engineerin, 2014.

[3] WEN Xin, LI Xin, ZHANG Xingwang. "The Application of MATLAB Neural Network”. Nation Defense Industry Press, 2015.(6):104-108.

[4] CHEN Chi. "Intelligent Analysis on the Malfunction Meter Based on the Electric Energy Data Acquisition System”. Electrical Measurement \& Instrumentation, 2014, 15: 18-22. 